\title{
THE ORIGIN OF CETACEA: MORPHOLOGICAL DIVERSITY OF ARCHAEOCETES FROM THE KULDANA FORMATION OF PAKISTAN
}

THEWISSEN* , J. G. M., Department of Anatomy, Northeastern Ohio Universities, College of Medicine, Rootstown, OH 44272, U. S. A.; HUSSAIN, S. T., Department of Anatomy, Howard University, College of Medicine, Washington, D. C. 20059, U. S. A.; MADAR, S. I., Department of Biology, Hiram College, Hiram, OH 44234, U. S. A.

Cetaceans are found throughout the early and middle Eocene Kuldana Formation of northern Pakistan, but they are most common near its base and near its top. Lower Kuldana cetaceans include Pakicetus, Ichthyolestes, and Nalacetus. They are found only in a fauna that includes terrestrial and freshwater elements in sediments that indicate a dry climate with channels that carried water only episodically. These cetaceans were certainly to a large extent terrestrial animals. Upper Kuldana cetaceans, such as Ambulocetus, are found in near-shore marine environments, as evidenced by the presence of bivalve banks and deltaic deposits. Ambulocetus was probably amphibious.

Three aspects of the morphology of Cetacea underwent dramatic change across the landwater interface. The first of these is feeding behavior, which is documented in part by dental morphology. Early cetaceans display a variety of tooth shapes and were ecologically diverse. There is, however, no adequate modern analogue for their molar morphology. Early cetacean dental morphology resembles that of mesonychians, suggesting that their diets $m$. iy have been similar.

Hearing also changed greatly, as is documented by the bony outer, middle, and inner ear anatomy. These changes are poorly documented, as fossils of ear bones are not available for all taxa. Some of the changes in ear morphology (especially the outer ear) have a clear functional link, but others (such as those of the middle ear) do not. The outer ear of Pakicetus resembles that of land mammals, whereas that of Ambulocetus is clearly intermediate between land mammals and marine cetaceans.

Locomotor evolution is also documented by the fossils and has a strong link to function. Locomotor morphology in modern swimmers correlates well with locomotor behavior, and the morphology of fossils can thus be used to predict their swimming mode. Fossils can then be used to test models for the origin of cetacean locomotion that are based on swimming in extant mammals. Postcranial remains of Pakicetus are scarce, but the skeleton of Ambulocetus suggests that swimming behavior in this cetacean resembled that of the sea otter Enhydra.

Cetaceans from the Kuldana Formation represent the earliest stages of life in the water. They document some of the changes that cetaceans underwent in their transition from land to sea. Combined with fossil cetaceans from other Eocene deposits of India and Pakistan, they showcase one of most dramatic evolutionary changes in mammalian evolution. 